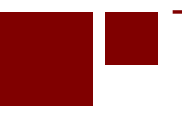

C E N T E R for RETIREMENT RE S E A R C H at BOSTON COLLEGE

\title{
RISING INEQUALITY IN LIFE EXPECTANCY BY SOCIOECONOMIC STATUS
}

Geoffrey T. Sanzenbacher, Anthony Webb, Candace M. Cosgrove, and Natalia S. Orlova

CRR WP 2017-2

April 2017

Center for Retirement Research at Boston College

Hovey House

140 Commonwealth Avenue

Chestnut Hill, MA 02467

Tel: 617-552-1762 Fax: 617-552-0191

http://crr.bc.edu

Geoffrey T. Sanzenbacher is a research economist at the Center for Retirement Research at Boston College (CRR). Anthony Webb is the research director of the Retirement Equity Lab at The New School's Schwartz Center for Economic Policy Analysis. Candace M. Cosgrove is a mathematical statistician at the U.S. Census Bureau. Natalia S. Orlova is a research associate at the CRR. The research reported herein was pursuant to a grant from the Alfred P. Sloan Foundation. The findings and conclusions expressed are solely those of the authors and do not represent the views of the Alfred P. Sloan Foundation, the Retirement Equity Lab at The New School's Schwartz Center for Economic Policy Analysis, the U.S. Census Bureau, or Boston College.

(C) 2017, Geoffrey T. Sanzenbacher, Anthony Webb, Candace M. Cosgrove, and Natalia S. Orlova. All rights reserved. Short sections of text, not to exceed two paragraphs, may be quoted without explicit permission, provided that full credit, including (C) notice, is given to the source. 


\begin{abstract}
Inequality in life expectancy is growing in the United States, but evidence is mixed regarding how much it has grown. Some studies have found that life expectancy has decreased for those with the lowest socioeconomic status (SES). Other studies have found that while inequality is rising, there have been life expectancy gains across the board. A primary difference in these studies is how SES is measured. Some studies use an absolute measure, such as years of school completed, while others use relative measures, such as a person's ranking of years of school completed compared to others born at the same time. This study uses regression analysis to assign people a relative education ranking and, in doing so, attempts to isolate the changing relationship between SES and mortality from the fact that certain education-based groups, especially high school dropouts, actually have a lower SES level today than in the past. The study finds that when SES is defined in this way - relatively - inequality in mortality by SES is increasing but life expectancies have also increased across SES groups. The study also finds that white women in the bottom of the education distribution have experienced the least improvement of any group. This research suggests that efforts to improve the finances of Social Security through higher retirement ages will have to reckon with the distributional effects of increasing inequality in mortality, but not with increases in mortality for large segments of the population.
\end{abstract}




\section{Introduction}

Studies on trends in mortality inequality come to different conclusions about the extent of its rise. Some research has found that life expectancies have actually decreased for those with the lowest socioeconomic status (SES). Other research has simply found rising inequality in life expectancy, but with improvements across the board. One of the major reasons for the different findings is that different measures of SES are being considered. Studies that use an absolute measure of SES, like high school completion as in Olshansky et al. (2012), tend to find increases in inequality so severe that low-SES individuals actually have lower life expectancies or higher mortality than in the past. On the other hand, studies that use relative rankings of SES, like the $25^{\text {th }}$ percentile of educational attainment as in Bound et al. (2014) or earnings as in Waldron (2007), tend to find rising inequality but no decrease in life expectancy for any group.

In studies that use absolute levels of SES, two things are potentially changing over time: 1) inequality in mortality between higher and lower SES groups; and 2) the composition of the low-SES group. For example, an individual born in 1925 who then dropped out of high school as roughly $40 \%$ of such individuals did - would still have been in the mainstream of economic life. An individual born in 1945 who did the same - as just $20 \%$ of such individuals did - was in a more disadvantaged economic minority. ${ }^{1}$ If more recent cohorts of high-school dropouts are dying earlier, it is unclear whether that is due to the increasing importance of SES in driving mortality or the fact that people born in 1945 were actually of a lower SES. And while the finding that high-school dropouts are living shorter lives is important, it is difficult to know exactly what is causing it. Is an increasingly unequal economy punishing low-SES individuals, or is the group being examined actually of an even lower SES today than it once was?

In theory, studies that use a relative rank of SES, like those below the $25^{\text {th }}$ percentile of educational attainment, hold the composition of the group being examined constant. But because education is not a continuous variable, breaking ties between people with the same level of education to assign a ranking can become a major methodological issue. For example, by the 1950 birth cohort, a person in the bottom $25^{\text {th }}$ percentile of the education distribution would have had a high school diploma and no college, but this group extended up into the $40^{\text {th }}$ percentile, with the number rising more for later cohorts. This fact means that either: 1 ) the lowest-SES group would begin getting bigger as more people fall into a tie; or 2) some individuals in the

\footnotetext{
${ }^{1}$ Goldin (1998).
} 
high-school graduating group need to be reassigned to the lowest-SES group to maintain the group's composition. Taking the first approach and allowing the group to change in size, as in Bound et al. (2014), could understate rising inequality by gradually including more and more better-educated people in the low-SES group. And using a variable with a more continuous characteristic, like earnings, in a relative SES ranking eliminates the problem of discrete categories but may exaggerate the problem of rising inequality since earnings, health, and ultimately mortality are correlated.

This study uses education, which is determined at a young age and thus limits the correlation to health, as its measure of SES and takes the second approach to dealing with ties by reassigning some individuals from higher education quartiles to lower ones to hold constant the size and composition of the group. The goal is to add to the literature by isolating the changing relationship of SES to mortality from the effect of the changing composition occurring within a absolute level of education. The risk in this approach is that individuals might be reassigned in a way that does not reflect their true SES, causing mortality inequality to be understated. For example, if high school graduates with no college education represent the $10^{\text {th }}$ to the $50^{\text {th }}$ percentile of the educational distribution, about $40 \%$ of the group (15\% of the population) need to be assigned to the lowest quartile. Simply assigning some of these individuals randomly from higher quartiles to the lower quartiles will understate inequality.

To mitigate this risk, we create education quartiles initially based on four absolute level of education: less than high school, high school no college, some college, and college graduates. Then, we apply a regression-based approach to reassign people from one of these four educational groups to another for birth cohorts when the observed group represents more than a fourth of the population. The idea is simple: reassign people to an educational quartile based on characteristics that are correlated with their level of education (e.g., earnings, industry of employment, race, family income, and the interactions of these variables). For example, a person born in 1925 may have been a high school dropout, but his other characteristics suggest that if he were born at a time when higher levels of education were more common, he might have attended college (e.g., high family income, working in a white-collar occupation, etc.). Our approach would be more likely to assign this person to the third- or fourth-quartile of the education distribution than to the first- or second quartile and more likely to be assigned to those 
quartiles than another. The end result is that within each birth cohort, each educational quartile is the same size and should reflect a constant representation of SES.

Of course, the approach is not without complications. For one, it requires use of a dataset - the National Longitudinal Mortality Study (NLMS) - that contains information both on death and on a variety of covariates that may correlate with education. While the NLMS satisfies the needs of the reassignment procedure, it is considerably smaller than population-level data used in other studies, such as the CDC Multiple Cause of Death Data used by Olshansky (2012) and Bound et al. (2014). ${ }^{2}$ Furthermore, because the NLMS is based off of the Current Population Survey (CPS), its sample members reside only in non-institutional settings. To ensure that the sample size and non-institutional population do not unduly alter the results, we will benchmark probabilities of death obtained from the NLMS to widely used probabilities maintained by the SSA that reflect the entire U.S. population. A final complication is that using a variable like income in the reassignment procedure may introduce some of the same issues discussed above namely that income at a point in time may be correlated with health at that time and ultimately mortality. While this concern is valid, income is used only as an adjunct to education when reassignment is needed. That being said, sensitivities of our approach to not using income were tested and the results of the study similar.

Our calculations show that mortality inequality has been increasing: between 1979 and 2011, men and women from the lowest educational quartile experienced age-adjusted average annual mortality improvements of $1.6 \%$ and $0.5 \%$ per year, respectively, compared to $2.4 \%$ and 1.2\% per year, respectively, for the highest quartile. The results indicate that increasing inequality is not simply a function of the changing composition of the lowest educated group but reflects an increasingly strong relationship between SES and mortality.

Mortality improvement, of course, directly translates to higher life expectancies, which we find have increased for all SES groups. In this paper, life expectancies are calculated assuming that individuals reaching 65 in 2011 have 2011 mortality as a 66 year old, 2011 mortality as a 67 year old, and so on - i.e., a “period” approach. The reason for this is simple - a “cohort” approach assumes the mortality improvements continue at the same pace into the future

\footnotetext{
${ }^{2}$ It is also worth noting that education data are only available on death certificates since 1989 and there is some concern regarding its accuracy. For example, see Rostron et al. (2010).
} 
and recent research casts doubt on this assumption. ${ }^{3}$ Given our period approach, our calculations indicate that between 1979 and 2011, period life expectancy at age 65 for men in the lowest to the highest educational quartiles increased by 4.1, 5.0, 5.4 and 5.9 years, respectively. The improvements are smaller but similarly unequal for women, at 1.3, 2.3, 2.5 and 3.7 years, respectively. All SES groups are living longer, but the gains are greater for the most educated.

Because recent work has also suggested that lower educated whites ages 45-54 have been particularly disadvantaged in terms of mortality - notably Case and Deaton (2015) - we also perform our calculations for whites only and use the same time period and ages used in the Case and Deaton study. We confirm their central result, finding that white men in the bottom half of the education distribution aged 45-54 saw their mortality rates increase at a rate of $0.5 \%$ annually between 1999 and 2011, with a larger increase of 2.0\% per year for women aged 45 to 54 .

The remainder of this paper is organized as follows: the next section summarizes the existing literature, the third describes the data; the fourth section describes the empirical analysis; the fifth section the results; and the sixth section provides a discussion as to where this paper fits into the recent literature. The final section concludes that rising inequality in mortality means programs like Social Security and Medicare must reckon with the distributional effects of any increase in the retirement or eligibility age, but that findings of increasing mortality likely apply only to small segments of the population.

\section{Literature Review}

Although this paper contends there is some disagreement as to the extent of widening mortality differentials by SES, the existence of differentials is well-established. One of the earliest studies on this topic is Kitagawa and Hauser (1973), who documented differences in mortality across SES as defined by education, race, income, and other covariates using death records linked to the 1960 Long-Form Census. Another cross-sectional study - using NLMS data for 1979-1989 - again found that high-SES individuals (as measured by race and education) have substantially lower mortality rates (Brown, Liebman, and Pollet 2002). More recently, Waldron (2013) found an inverse correlation between lifetime earnings and mortality extending up through most of the income distribution. It is clear mortality differentials exist across groups as defined by SES - but how much worse are these differentials?

\footnotetext{
${ }^{3}$ Jemal et al. (2015).
} 
Early studies examining trends in mortality inequality over time found mixed results. ${ }^{4}$ Rogot, Sorlie, and Johnson (1992) found that education-related mortality differentials were the same in 1985 as those found by the Kitagawa and Hauser (1973) study mentioned above. In contrast, Pappas et al. (1993) reported widening SES mortality differentials between 1960 and 1986. However, more recent research has consistently found increases in mortality differentials across SES, although the size of that increase differs.

Some of the newer studies have used income as the primary measure of SES. Waldron (2007) used lifetime labor market earnings as a proxy for SES and found that mortality has declined more rapidly among individuals in the top half than among those in the bottom half of the earnings distribution. Cristia (2009) similarly looks at lifetime earnings - this time in quintiles - and finds substantial increases in inequality in life expectancy between 1983 and 2003. One problem with using earnings (even lifetime earnings) as a proxy for SES is that earnings, unlike education, are affected by health shocks. Using earnings as a proxy for SES may exaggerate SES mortality differentials if health shocks both reduce earnings and increase mortality. To alleviate this concern, other studies have focused on education to measure SES.

One study in this vein by Cutler et al. (2011) divided a sample from the National Nutritional and National Health Examination Study into two absolute educational groups - those with some college and those with less than some college and found increasing mortality differentials. As mentioned in the introduction, Olshansky et al. (2012) also use absolute levels of education and claim a three-year reduction in age-20 life expectancy among white men with less than a high school education, with no corresponding reductions among blacks and Hispanics. Case and Deaton (2015) also use an absolute measure of education for low-SES, focusing on those with a high school education or less and no college. This research also indicates increases in mortality - this time for white men and women ages 45-54 between 1999 and 2013.

Studies that use relative measures of education have come to slightly different conclusions. When Bound et al. (2014) refine the estimates of Olshansky et al. using the same data but with an educational ranking instead of absolute levels (i.e., the bottom quartile by grade completed is used instead of less than high school) they find the adjustment eliminates the

\footnotetext{
${ }^{4}$ Many studies of mortality trends, for example Lee and Carter (1992) and Jemal et al. (2015), do not decompose trends by SES.
} 
finding that less-educated men experienced a reduction in age-20 life expectancy from 1990 to 2008. Bound et al. also point out that low-educated women appear to be especially vulnerable, a funding confirmed by other research, for example Kindig and Cheng (2013). Finally, Bosworth, Burtless, and Zhang (2015) examine rising mortality inequality by both income and relative education for sample members in two relatively small datasets, the Health and Retirement Study (HRS) and the Census Bureau's Survey of Income and Program Participation (SIPP). In the SIPP sample, they find evidence of rising inequality but no decreases in life expectancy. But in the HRS sample, they do find evidence of decreasing life expectancy, especially when income is the primary measure of SES. This study makes clear that different datasets and different measures of SES can result in different conclusions about the severity of the rise in inequality.

The present study adds to this literature by using a measure of SES - the predicted educational quartile - that holds constant the composition of the groups being compared (as income naturally does) and eliminates the issue of the potential correlation between earnings and health that may cause some exaggeration of rising inequality in studies that use income as their primary measure.

\section{Data and Sample}

As mentioned above, this study uses the National Longitudinal Mortality Study (NLMS) to estimate trends in mortality by SES. The NLMS consists of individual-level data from the CPS and from the 1980 Census cohort - which provide data on SES - matched to data from death certificates obtained from the National Center for Health Statistics. The NLMS includes 33 samples from the Annual Social and Economic Supplements to the CPS - one sample from March 1973 and samples collected each year from March 1979 to March 2011. The NLMS also includes five samples taken from the basic monthly CPS data for February 1978, April 1980, August 1980, December 1980, and September 1985, and from one 1980 Census cohort. ${ }^{5}$ These 39 samples include SES data on 3.8 million individuals, of which just 200,000 (5\%) are excluded from the NLMS due to insufficient information to match them to death certificates. Of the remaining 3.6 million observations included in the NLMS, there were over 500,000 cases of

\footnotetext{
${ }^{5}$ Information on year of birth and CPS sample year are not available in the public-use version of the NLMS. Because these variables are critical to the analysis presented here, all analyses were conducted on restricted-access data through employees at the U.S. Census Bureau.
} 
recorded mortality in the 2011 data, the last year that the CPS samples were matched to death certificates.

Due to its structure, the NLMS contains two groups of variables collected at different points in time. For each individual, demographic and socioeconomic characteristics such as age, education, gender, income, earnings, and employment status, are obtained at the time of their CPS or Census interviews, marking the beginning of their appearances in the NLMS. For individuals who die between their sample year and 2011, additional information on date, cause, and location of death that is collected from death certificates is included.

Our initial sample consists of all NLMS cohorts beginning in 1979 or later except for the 1980 Census cohort, which excludes information on education. The initial sample consists of individuals born between 1877 and 1959 and ages 25 or older at their sample year, for a total of 1.7 million observations. After assigning individuals to educational quartiles, the final sample used to conduct the analysis is slightly smaller - 1.5 million people - since it excludes individuals missing data for variables used directly in this reassignment: ethnicity, gender, industry and occupation (if working), family income, family size, residence in a Metropolitan Statistical Area (MSA), and state. See Table 1 for detail on how the sample is restricted from the full sample of all available individuals to the final sample used in estimation after eliminating individuals with missing information. Table 2 shows that the sample consists of over 17 million person-year observations with at least 100,000 observations across all decades and age groups.

\section{Empirical Analysis}

The empirical analysis has several steps. First, the NLMS data are benchmarked against a common source of mortality data - U.S. Social Security Administration (SSA) period mortality tables. The second step is to assign people to an educational quartile so as to maintain the distribution of education over time. The third step is to use the NLMS data to calculate annual mortality rates by year, education, and gender. These mortality rates serve as inputs into a mortality regression that identifies levels and changes over time in mortality rates by SES. 


\section{Benchmarking the NLMS Data}

To confirm consistency with other widely used mortality data, we first benchmark the NLMS data against SSA cohort life tables. ${ }^{6}$ The goal of this comparison is to ensure that the sample used by the NLMS - which is both smaller and selected to include only those not residing in institutions when compared to that used by SSA - compares well to a set of widely used mortality tables based on the entire population. The SSA mortality tables show the probability of death by the next birthday for individuals at age $a$ and born in year $t$. To conduct the comparison, NLMS data for individuals from the 1877-1959 birth cohorts are used to calculate probability of deaths using the following formula:

$$
q_{a, t}=\frac{l_{a, t}-l_{a+1, t}}{l_{a, t}}
$$

where $q_{a, t}$ is the probability of death between age $a$ and $a+1$ for an individual born at time $t$ and $l_{a, t}$ is the number of individuals alive at age $a$ born at time $t$. For example, $m_{75,1920}$ would be the probability of death between age 75 and 76 for an individual born in $1920 .^{7}$

To compare the probability of death calculated in eq. (1) to those provided by the SSA, we calculate the unweighted average probability of death at each age across the 1877-1959 birth cohorts in the NLMS data. ${ }^{8}$ We compare these averages with the corresponding values reported in SSA's cohort life tables for the 1877-1959 birth cohorts. ${ }^{9}$ Figs. 1a (men) and 1b (women) report the results of this comparison. Fig. 1a shows that the NLMS data for men closely match SSA life tables, with a small discrepancy above age 91, at which point the NLMS sample shows

\footnotetext{
${ }^{6}$ The U.S. Social Security Administration (SSA) calculates mortality rates using different methods for different years of death. To calculate mortality rates for 1900-1967, SSA divides the number of deaths for each age and gender from the National Center for Health Statistics by the mid-year Census estimate of the population for that age and gender. After 1968, the SSA uses this same method for all individuals under age 65, but uses Medicare data to calculate the mortality rate for individuals over age 65. Medicare data have the advantage of containing the number of deaths and the number of individuals alive for the population within the same dataset.

${ }^{7}$ In the NLMS, a small fraction of individuals included in the sample have not yet been matched to a death certificate, despite having obviously reached ages where they are deceased. If they are not accounted for, these socalled immortals result in mortality rates that are artificially low at high ages. To account for this data issue, we identify the number of individuals over 105 years old and alive in 2011 for each birth cohort and subtract these individuals from the denominator of eq. (1) for the years in which they were in the sample.

${ }^{8}$ An alternative approach would have been to weight both the SSA probabilities and the NLMS probabilities by the share of NLMS deaths at a given age due a given birth cohort, i.e., weighting the calculations based on where the most data on death is available in the NLMS. The comparison between the SSA and NLMS death probabilities are similar under this approach.

${ }^{9}$ We include only those age-year combinations for which we have observations and for which there are at least five NLMS observations.
} 
slightly lower mortality. At high ages, the NLMS samples become quite small so some discrepancies are not surprising, especially when one considers that those living in nursing homes at the time of the CPS sample are not included in the NLMS. For women, Fig. 1b shows the two series match closely at all ages. Figs. $1 \mathrm{a}$ and $1 \mathrm{~b}$ confirm that the NLMS data are largely representative of the mortality experience of the relevant birth cohorts for the full population, as estimated by the SSA.

\section{Reassigning Educational Attainment}

A major contention of this paper is that using an individual's level of educational attainment - high school, college, etc. - to measure SES may overstate changes in the mortality gap over time that are due to SES itself. This overstatement is possible because, for example, the share of high school dropouts has become much smaller over time and represents a more disadvantaged SES group than in the past. A widening mortality gap between dropouts and those with more education could represent either the actual impact of rising inequality by SES or the increasing disadvantage of this least-educated group.

To address this issue, we reassign educational attainments so that, for each birth cohort, an equal number of individuals is in each educational quartile. We first estimate the following ordered probit model:

$$
y^{*}=x \beta+e
$$

where $y=0$ if $y^{*}$ (the exact but unobserved dependent variable) is $\leq \alpha_{1}$, the dividing line between less than high school and high school education; $y=1$ if $\alpha_{1}<y^{*} \leq \alpha_{2}$, the dividing line between high school and some college; $y=2$ if $\alpha_{2}<y^{*} \leq \alpha_{3}$, the dividing line between some college and college graduation; $y=3$ if $\alpha_{3}<y^{*}$, and $x$ is a vector of correlates of educational attainment including birth year, ethnicity, gender, industry, occupation, family income decile, family size, residence in an MSA, and state. In this specification, the ethnicity variable is defined as white non-Hispanic, black non-Hispanic, other non-Hispanic, or Hispanic; agriculture is grouped with manufacturing and construction, trades with personal services and entertainment; and occupation is defined as white or blue collar. Family income deciles are defined within birth cohorts and separately for households where the male adult (or female adult in female-only 
households) is working vs. retired. To ensure maximum flexibility in the reassignment procedure the family income decile variable is interacted with gender, race, and ethnicity.

Once the regression is run, the reassignment procedure proceeds as follows. We initially place those with less than a high school education in the bottom quartile, those with a high school education in the second quartile, those with some college in the third quartile, and college graduates in the top quartile. If more than $25 \%$ of individuals in a given birth cohort have a college degree, we reassign individuals from the top to the third quartile to reduce the size of the top quartile to $25 \%$ of the total. The probability of being moved is proportional to the probability that someone with that individual's characteristics would not have graduated from college based on the results from equation (2). Marginal, low-probability college graduates (e.g., low household income, blue-collar job) are more likely to be reassigned to a lower educational quartile. We then proceed in like fashion to reassign individuals with some college education to the second quartile, and those with a high school education to the bottom quartile, until we have equal numbers in each quartile. Among older birth cohorts, more than a quarter of individuals failed to graduate from high school, so the procedure for these cohorts starts with those with less than a high school education and works up through the quartiles.

\section{Constructing Period Life Tables}

We then use the NLMS data to construct period mortality tables that vary with age, year, gender, and reassigned educational quartile. Constraints are imposed, however, because even with this large sample, it is infeasible to allow mortality rates to vary flexibly with all of the above factors. Specifically, mortality is assumed to increase exponentially with age, a feature of mortality data that previous research dating back to Gompertz (1825) has shown to hold true until advanced ages. We further assume that, within each gender and SES group, all age groups experience the same annual percentage changes in their mortality rates.

These assumptions lead to the following model for each gender and educational quartile:

$$
\ln \left(m_{a, t}\right)=\beta_{0}+\beta_{1}(a-52)+\beta_{2}(t-1979)
$$

where $\beta_{0}$ is the logged mortality rate at age $52, \beta_{1}$ is the exponential rate at which mortality increases with age, $a$, $t$ is the year the mortality probability from (1) was calculated, and $\beta_{2}$ is the annual percentage rate of decline in mortality from 1979 onward. To ensure the model fits the 
death rate the best when the most deaths occur, the regression is run using weights that reflect the share of the quartile/gender group that die at a given age.

\section{Results Using Educational Quartiles}

This section presents two types of results: 1) the regression results from the mortality models; and 2) the corresponding increases in life expectancy by education.

\section{Mortality Models}

Table 3 illustrates the results of estimating eq. (1) separately for men and women and the sample overall, but without making distinctions for educational quartile. ${ }^{10}$ This pooled approach provides a useful benchmark of the NLMS data against other mortality data. The "overall” result indicates that between 1979 and 2011, the annual reductions in mortality averaged 1.1 percentage points per year. This rate of decline is slightly higher than that estimated by Social Security for a similar time-period - 1.0\% per year between 1982 and 2011.

But the proximity of these estimates between the NLMS and SSA data mask larger discrepancies between genders. While the NLMS and SSA data suggest similar rates of decline for women -0.7 versus $0.6 \%$ per year, respectively - the estimates are farther apart for men. The NLMS data show men experienced annual declines in mortality averaging $2.0 \%$ between 1979 and 2011 while the result from SSA is $1.3 \%$ for a similar time period (1982 to 2011). ${ }^{11}$ While other authors have detected mortality improvements around, and even above, 2\% for men at certain ages and for some time periods, ${ }^{12}$ this finding causes us to proceed with caution. Specifically, we will approach all life expectancy calculations from a “period” approach assuming mortality rates become fixed at a certain point in time - to avoid projecting mortality improvements observed in the NLMS data between 1979 and 2011 into the future. This approach seems especially prudent since some developments that may have caused mortality

\footnotetext{
${ }^{10}$ In these regressions, each age and gender cell is weighted by the share of deaths in the year that occurred for that cell. In other words, the regression attempts to fit mortality rates within a year placing the most weight on ages with the most deaths.

${ }^{11}$ U.S. Social Security Administration, "Long-Range Demographic Assumptions for the 2015 Trustees Report." The finding of agreement overall in the time trend but disagreement by gender is statistically possible, because the overall regression constrains the age coefficient to be the same across genders, whereas more flexibility is allowed in the separate regressions.

${ }^{12}$ For example, Lu and Wong (2011) report yearly mortality improvements for males ages 60 to 90 ranging from 1.5 to 2.5 percent using the Human Mortality Database from 1995-2006.
} 
rates to improve over the past 30 years will likely not continue into the future (e.g., smoking cessation), while other trends may offset mortality improvements (e.g., higher rates of obesity). Furthermore, recent research suggests that the growth in mortality has slowed recently across the population. ${ }^{13}$

Table 4 shows the regression results by gender and educational quartile. The first four rows of results are for men and the second four rows are for women. These coefficients measure mortality per 100 of the population. For example, if we wished to use the NLMS data to predict mortality among 80-year-old men in the bottom quartile in 1990, we would perform the following calculation:

$$
m_{a, t}=\exp (0.201+0.077(80-52)-0.016(1990-1979))
$$

yielding a predicted mortality rate of 8.9 per 100 , or 0.089 .

Table 4 shows that across both genders and for each education quartile, mortality rates increase with age and decrease over time, as can be seen through the positive coefficients on the age variable and the negative coefficients on the years that have passed since 1979. The results also show significant differences, based on education quartile, in mortality reductions over time, as is shown in the second column of Table 5. The results indicate that men and women in the top quartile have enjoyed significantly faster declines in mortality from 1979 through 2011 than have those in lower quartiles. ${ }^{14}$ For men, annual reductions in mortality rates - ranging from the lowest to highest quartiles of educational attainment - are estimated at 1.6, 2.0, 2.2, and 2.4\%, , respectively (as shown in the second column of Table 4). The pattern is similar for women, with smaller annual reductions in all educational quartiles than for men $-0.5,0.9,1.0$, and $1.2 \%$, respectively. ${ }^{15}$

\footnotetext{
${ }^{13}$ Jemal et al. (2015).

${ }^{14}$ In Table 4, the difference for men between the highest and third educational quartiles is visible in the third row and is a statistically significant $0.3 \%$. For women, the corresponding difference is $0.4 \%$ and is also statistically significant.

${ }^{15}$ In the event the age distribution was changing over time, then the failure to include a non-linear term with age could bias the results. As a sensitivity, we re-ran the regressions with both age and age-squared terms and found similar results. For men the declines were $1.5 \%, 2.0 \%, 2.2 \%$, and $2.5 \%$ per year and for women $0.5 \%, 1.0 \%, 0.9 \%$, and $1.2 \%$. Another concern is that data quality at age 85 and over can be compromised. Restricting the analysis to just individuals 84 and under has a small effect on estimated annual decline, which is $1.5 \%, 2.1 \%, 2.3 \%$, and $2.9 \%$ for men and $0.4 \%, 1.0 \%, 1.1 \%$, and $1.6 \%$ for women. If the data are believed, these results suggest that those with high education saw faster improvement at high ages than others.
} 


\section{Life Expectancy by Educational Quartile}

Of course, improving mortality leads to longer life expectancy. Table 6 uses the estimates presented above to obtain life expectancies for those who survive to age 65 (the current full retirement age) and, separately, at age 22. The results reported in Table 6 are so-called "period" estimates of life expectancy. Again, these estimates assume that mortality rates become fixed at their 1979 or 2011 levels. For example, this means that individuals who reach 65 in 2011 do not continue to experience mortality improvements as they age - e.g., when 67 in 2013 they will have the same mortality as a 67 year-old had in 2011, and so on. ${ }^{16}$ Regarding inequality in life expectancy this approach does not project a widening gap in mortality into the future.

Using this approach, men who survive to age 65 in 1979 had life expectancies - ranging from the lowest to highest educational quartiles - of 77.5, 77.7, 77.8, and 79.0 years, respectively. By 2011, men experienced life expectancy increases of 4.1, 5.0, 5.4, and 5.9 years. Men at age 22 have lower life expectancies, 68.9, 70.6, 71.3, and 74.4 respectively, but saw bigger improvements between 1979 and 2011 at 6.2, 7.3, 7.7, and 7.7. Clearly, the highest gains were enjoyed by the highest quartiles of the education distribution. The corresponding ages for 65-year-old women in 1979 were 82.2, 82.5, 82.9, and 83.5 years, with increases by 2011 of 1.3, 2.3, 2.5, and 3.1 years. For women at age 22, the corresponding ages were 77.0, 78.6, 79.3, and 80.7 with improvements of 1.8, 3.0, 3.2, 3.7. For both men and women, both the age-65 and age 22 life expectancies increased across all educational groups and increased the most in the top quartile. Figures 2A and 2B illustrate the change in survival probabilities for the bottom quartile of assigned education and the top quartile for men and women respectively. The figures clearly illustrate the rising inequality between the two quartiles and the fact that women generally saw much smaller declines in mortality than men over this period.

\section{Discussion}

The results show that when the composition of the lowest education group is held constant through the reassignment procedure, all groups experienced at least some mortality

\footnotetext{
${ }^{16}$ This approach is in contrast to a "cohort" based approach, which allows mortality to reflect age and birth year. For example, a person born in 1946 who reaches 65 in 2011 experiences 2011 mortality rates for a 65-year-old in 2011 and 2012 mortality rates for a 66-year-old in 2012. In contrast, a 65-year-old born one year later, in 1947, reaches 2012 mortality rates for a 65-year old in 2012 and 2013 mortality rates for a 66-year old in 2013.
} 
improvement between 1979 and 2011. This finding is consistent with that of Bound et al. (2014), who found that when individuals were assigned to the lowest educational group based on their relative level of education ( $25^{\text {th }}$ percentile and below) instead of their absolute level (e.g., high school dropouts) no group experienced a decline in life expectancy. The result is also similar to studies that have used earnings as a relative measure of SES - for example, the position in the earnings distribution as in Waldron (2007) - and that find rising inequality over time but not increases in mortality. The reason some studies have found that individuals with low levels of education have seen decreases in longevity - for example, Olshansky et al. (2012) results from two changes occurring over time: 1) the rising inequality documented in this study; and 2) the fact that high school dropouts have become a more disadvantaged economic minority. In eliminating the second effect, the use of a relative measure isolates the first and shows that SES itself seems to have a stronger relationship to mortality today than in the past.

Still, a direct comparison to the results presented here and to other recent results in the literature is difficult, because these studies typically have segmented the samples by race and because the studies typically use a shorter time period and/or different age ranges. To facilitate such a comparison we re-ran our analysis - including the reassignment procedure - on whites only. Regressions were then estimated for 1990-2011 - the same time period used in Olshansky et al. (2012) and Bound et al. (2014) - and again for the 1999-2011 time period and sample used in Case and Deaton (2015) only for individuals between ages 45 and 54. ${ }^{17}$

The results of this exercise are contained in Table 7. For the longer period, 1979 to 2011, white men look remarkably similar to the entire sample, but white women look quite different. In this three-decade period, white women in the lowest quartile of the education distribution saw annual mortality improvements of just $0.1 \%$, compared to $1.2 \%$ for white women in the highest quartile. Figure 3 illustrates this result using survival curves for white men and women in the bottom quartile of the education distribution; there is almost no change in women's survival probabilities between 1979 and 2011 while men did see improvements. The result is similar for the period 1990-2011, with the least-educated white women seeing only small improvements while men see larger ones. Like this study, Bound et al. (2014) also highlights the fact that white women with less education have tended to see smaller improvements in mortality than similarly educated white men. The finding suggests that the increase in mortality found among white male

\footnotetext{
${ }^{17}$ Case and Deaton used data through 2013, but the last NLMS match to death certificates occurred in 2011.
} 
high school dropouts by other studies over this period is largely a function of the increasing disadvantage of this particular group as it has shrunk over the decades.

When restricting the sample further to include only observations between 1999 and 2011 and only those ages 45-54, we find results similar to those reported by Case and Deaton (2015). Because Case and Deaton (2015) conducted their analysis on those with a high school degree or less (but no college), we reran this portion of our analysis combining the lowest two quartiles of education, which roughly represents the same group (today, roughly half of individuals attend at least some college). Our findings are consistent with theirs: both white men and women in this age bracket saw an increase in mortality over this time period, with women faring worse. The consistency of our findings with theirs is not surprising - our reassignment procedure should have almost no effect for this group, since roughly half of whites who were between the ages of 45 and 54 in 1999-2011 had a high school degree or less. Furthermore, the result is consistent with the observation of others that had Case and Deaton split their sample by gender, which they did not, they would have found women experienced a much larger increase than men. ${ }^{18}$

This comparison to the literature highlights several findings of this paper. First, inequality in mortality is increasing and this is not due to the fact that the composition of education has changed over time. Even when holding constant the share of people in each educational group, as we do here, those with less education have seen smaller improvements in mortality. Second, once the composition of each educational group is held constant, actual increases in mortality are not observed except for the same subset of whites as in Case and Deaton (2015). Third, over the last several decades, women have seen smaller mortality improvements than men, and this finding has been especially true for the least educated women. Taken together, the findings suggest that future research should explore why economic inequality seems to have a larger effect on mortality today than it had in the past and, in particular, why the effect has been especially strong for less-educated women.

\section{Conclusion}

This paper adds another piece of evidence to the debate on mortality inequality. The results suggest that mortality inequality is worsening over time, but also that individuals across the SES spectrum are living longer than in the past. By holding constant the size and economic

\footnotetext{
${ }^{18}$ For example, see Aron et al. (2015).
} 
composition of the educational distribution throughout its analysis, this paper has tried to separate the increasing effects of SES on mortality from the fact that the distribution of absolute levels of education has been changing over time as has its relationship to SES. The fact that even after completing this exercise mortality inequality is increasing highlights a growing relationship between SES and life expectancy. This finding must be kept in mind as the U.S. struggles to bring the cost of Social Security and Medicare under control and considers increasing the retirement age or beneficiary age to do it.

The goal of future research is to determine why inequality is increasing so much. Plausible explanations include increasing economic stress due to the well-documented shift towards more-skilled labor and/or changing family structure, which has seen marriage rates decline and divorce rates increase for the less-educated relative to the most-educated. Whatever the explanation, future research must focus both rising inequality and also on why women seem to be especially affected. 


\section{References}

Aaron, H. J. \& G. Burtless. (2013). Closing the deficit: How much can later retirement help? Washington, DC: The Brookings Institution Press.

Andreev, K. \& J. Vaupel. (2005). "Patterns of mortality improvement over age and time in developed counties: Estimation, presentation, and implications for mortality forecasting.” Paper Presented at Population Association of America Annual Meeting. Philadelphia, PA.

Aron, L., L. Dubay, E. Waxman, S. Martin. 2015. “To Understand Climbing Death Rates Among Whites, Look to Women of Childbearing Age.” Health Affairs Blog.

Bell, F. C. \& M. L. Miller. (2005). “Life tables for the United States Social Security area 19002100.” Actuarial Study No. 120. Washington, DC: U.S. Social Security Administration.

Bound, J., A. Geronimus, J. Rodriguez, \& T. Waidmann. (2014). “The implications of differential trends in mortality for Social Security policy.” Paper Presented at $16^{\text {th }}$ Annual Meeting of the Retirement Research Consortium. Washington, DC.

Brown, J., J. B. Liebman, \& J. Pollet. (2002). Appendix: estimating life tables that reflect socioeconomic differences in mortality. In M. Feldstein and J. B. Liebman (Ed.), The distributional aspects of Social Security and Social Security reform (pp. 447-457). Chicago, IL: University of Chicago Press.

Bosworth, B., G. Burtless, and K. Zhang. (2015). "Later Retirement, Inequality in Old Age, and the Growing Gap in Longevity Between Rich and Poor.” Economics Studies at Brookings.

Case, A. and A. Deaton. (2015). "Rising morbidity and mortality in midlife among white nonHispanic Americans in the 21st century.” Proceedings of the National Academy of Sciences, 112(49), 15078-15083.

Cristia, J. P. (2009). "Rising Mortality and Life Expectancy Differentials by Lifetime Earnings in the United States.” Journal of Health Economics, 28(5), 984-995.

Cutler, D. M. (2009). “Estimating work capacity among near elderly and elderly men.” Working Paper 09-18. Cambridge, MA: National Bureau of Economic Research.

Cutler, D. M., F. Lange, E. Meara, S. Richards-Shubik, \& C. J. Ruhm. (2011). “Rising educational gradients in mortality: The role of behavioral risk factors.” Journal of Health Economics, 30 (6), 1174-1187.

Gavrilov, L. A. \& N. S. Gavriloca. (2011). "Mortality measurement at advanced ages: A study of the Social Security Administration death master file.” North American Actuarial Journal, 15 (3), 432-447. 
Goldin, C. (1998). "America's graduation from high school: The evolution and spread of secondary schooling in the twentieth century.” Journal of Economic History 58 (2), 345374.

Gompertz, B. (1825). "On the nature of the function expressive of the law of human mortality and on a new mode of determining the value of life contingencies." Philosophical Transactions of the Royal Society of London, 115, 513-585.

Haverstick, K., M. Sapozhnikov, R.t K. Triest, \& N. A. Zhivan. (2007). “A new approach to raising Social Security's earliest eligibility age.” Working Paper 2007-19. Chestnut Hill, MA: Center for Retirement Research at Boston College.

Jemal, A., J. Ma, E. M. Ward, and R. L. Siegel. (2015). “Temporal Trends in Mortality in the United States 1969-2013. Journal of the American Medical Association, 314(16), 17311739.

Johnson, N. E. (2000). "The racial crossover in comorbidity, disability, and mortality.” Demography, 37 (3), 267-283.

Kindig, D.A. and E. R. Cheng. (2013). "Even as Mortality Fell in Most US Counties, Female Mortality Nonetheless Rose in 42.8 Percent of Counties From 1992 to 2006.” Health Affairs, 32(3), 451-458.

Kitagawa, E. M. \& P. M. Hauser. (1973). Differential mortality in the United States: A study in socioeconomic epidemiology. Cambridge, MA: Harvard University Press.

Lee, R. D. \& L. R. Carter. (1992). "Modeling and forecasting U.S. mortality.” Journal of American Statistical Association, 87 (419), 659-671.

Leonesio, M. V., D. R. Vaughn, \& B. Wixon. (2003). "Increasing the early retirement age under Social Security: Health, work, and financial resources." Health and Income Security for an Aging Workforce No. 7. Washington, DC: National Academy of Social Insurance.

Lu, J. \& W. Wong. (2011). "Mortality improvement in the USA: Analysis projections and extreme scenarios." Paper Presented at Living to 100 Symposium. Orlando, FL.

Lynch, S. M., J. S. Brown, \& K. G. Harmsen. (2003). "Black-white differences in mortality compression and deceleration and the mortality crossover reconsidered." Research on Aging, 25 (3), 456-483.

Monk, C., J. A. Turner, \& N. A. Zhivan. (2010). "Adjusting Social Security for increasing life expectancy: effects on progressivity.” Working Paper 2010-9. Chestnut Hill, MA: Center for Retirement Research at Boston College.

Munnell, A. H. (2015). “The average retirement age - an update.” Issue in Brief 15-4. Chestnut Hill, MA: Center for Retirement Research at Boston College. 
Munnell, A. H. \& J. Libby. (2007). “Will people be healthy enough to work longer?” Issue in Brief 7-3. Chestnut Hill, MA: Center for Retirement Research at Boston College.

Olshansky, S. J., T. Antonucci, L. Berkman, R. H. Binstock, A. Boersch-Supan, J. T. Cacioppo, B. A. Carnes, L. L. Carstensen, L. P. Fried, D. P. Goldman, J. Jackson, M. Kohli, J. Rother, Y. Zheng, \& J. Rowe. (2012). "Differences in life expectancy due to race and educational differences are widening, and many may not catch up.” Health Affairs, 31 (8), 1803-1813.

Panis, C., M. Hurd, D. Loughran, J. Zissimopoulos, S. Haider, \& P. St. Clair. (2002). “The effects of changing Social Security Administration's early entitlement age and the normal retirement age.” DRU-2903-SSA. Santa Monica, CA: RAND.

Pappas, G., S. Queen, W. Hadden, \& G. Fisher. (1993). "The increasing disparity in mortality between socioeconomic groups in the United States, 1960 and 1986.” New England Journal of Medicine, 329 (2), 103-109.

Rogot, E., P. D. Sorlie, \& N. J. Johnson. (1992). "Life expectancy by employment status, income, and education in the national longitudinal mortality study." Public Health Reports, 107 (4), 457-461.

Rostron, B.L., J.L. Boles, E. Arias. (2010). "Education Reporting and Classification in the United States.” National Center for Health Statistics, Vital Health Statistics, 2(151).

Turner, J. A. (2007). "Work at older ages: Is raising the early retirement age an option for Social Security reform?” Working Paper 2007-13. Chestnut Hill, MA: Center for Retirement Research at Boston College.

U.S. Social Security Administration. (2015). The long-range demographic assumptions for the 2015 trustees report, Table 2.2. Washington, DC.

Waldron, H. (2007). "Trends in mortality differentials and life expectancy for male Social Security-covered workers, by socioeconomic status.” Social Security Bulletin, 67 (3), 128.

. (2013). "mortality differentials by lifetime earnings decile: implications for evaluations of proposed Social Security law changes." Social Security Bulletin, 73 (1), 1-37.

Wang, H., A. E. Schumacher, C. E. Levitz, A. H. Mokdad, \& C. J. L. Murray. (2013). “Left behind: Widening disparities for males and females in U.S. county life expectancy, 19852010.” Population Health Metrics, 11 (8), 1-15.

Weller, C. E. (2005). "Raising the retirement age for Social Security: Implications for low wage, minority, and female workers.” CAP Economic Policy Report. Washington, DC: Center for American Progress. 
Yao, L. \& S. A. Robert. (2011). "Examining the racial crossover in mortality between african american and white older adults: A multilevel survival analysis of race, individual socioeconomic status, and neighborhood socioeconomic context.” Journal of Aging Research, June, 1-8. 
Table 1. Sample Sizes, by Birth Year

\begin{tabular}{lr}
\hline & Number of individuals \\
\hline Total sample & $3,731,062$ \\
Drop 1980 Census cohort & $3,606,717$ \\
Drop non-relatives to respondent & $3,370,151$ \\
Drop if born after 1960 or younger than 25 & $1,601,534$ \\
Drop if missing variables needed for education reassignment & $1,537,686$ \\
Final sample & $1,536,093$ \\
& \\
Final sample by birth year & \\
$1877-1890$ & 1,754 \\
$1891-1895$ & 5,579 \\
$1896-1900$ & 13,756 \\
$1901-1905$ & 26,717 \\
$1906-1910$ & 43,388 \\
$1911-1915$ & 63,966 \\
$1916-1920$ & 84,119 \\
$1921-1925$ & 112,443 \\
$1926-1930$ & 126,344 \\
$1931-1935$ & 127,556 \\
$1936-1940$ & 138,164 \\
$1941-1945$ & 168,688 \\
$1946-1950$ & 218,063 \\
$1951-1955$ & 245,072 \\
$1956-1959$ & 160,484 \\
\hline
\end{tabular}

Source: Tabulations from restricted National Longitudinal Mortality Study (NLMS) data provided by the U.S. Census Bureau, 1979-2011. 
Table 2. Number of Person-years, by Observation Period, Age, and Gender

\begin{tabular}{cc}
\hline Men & Person-year observations \\
\hline Aged 25 to 54 & 150,987 \\
$1979-1989$ & 333,818 \\
$1990-2000$ & 585,709 \\
$2001-2011$ & \\
Aged 55 to 64 & 490,403 \\
$1979-1989$ & 895,394 \\
$1990-2000$ & $1,731,101$ \\
$2001-2011$ & \\
Aged 65 to 74 & 309,978 \\
$1979-1989$ & 641,109 \\
$1990-2000$ & 941,905 \\
$2001-2011$ & \\
Aged 75+ & 199,683 \\
$1979-1989$ & 500,823 \\
$1990-2000$ & 915,665 \\
$2001-2011$ & \\
Women & \\
Aged 25 to 54 & 168,131 \\
$1979-1989$ & 366,337 \\
$1990-2000$ & 642,086 \\
$2001-2011$ & \\
Aged 55 to 64 & 559,559 \\
$1979-1989$ & $1,011,936$ \\
$1990-2000$ & $1,913,201$ \\
$2001-2011$ & 399,546 \\
Aged 65 to 74 & 804,914 \\
$1979-1989$ & $1,122,521$ \\
$1990-2000$ & 349,480 \\
$2001-2011$ & 864,125 \\
Aged 75+ & $1,452,087$ \\
$1979-1989$ & \\
$1990-2000$ & \\
$2001-2011$ &
\end{tabular}

Source: Tabulations from restricted National Longitudinal Mortality Study (NLMS) data provided by the U.S. Census Bureau, 1979-2011. 
Table 3. Pooled Regression Results

\begin{tabular}{lrcc}
\hline & \multicolumn{1}{c}{ Age } & Years since 1979 & Constant \\
\hline \multirow{2}{*}{ Men } & 0.085 & -0.020 & -0.106 \\
& $(0.001)$ & $(0.001)$ & $(0.018)$ \\
Women & 0.091 & -0.007 & -0.869 \\
& $(0.001)$ & $(0.001)$ & $(0.020)$ \\
Overall sample & 0.085 & -0.011 & -0.505 \\
& $(0.001)$ & $(0.001)$ & $(0.019)$ \\
\hline
\end{tabular}

Source: Authors' calculations using tabulations from restricted NLMS data provided by the U.S. Census Bureau, 1979-2011.

Table 4. Regression Results, by Educational Quartile

\begin{tabular}{lrcr}
\hline & Age & Years since 1979 & Constant \\
\hline Men & & & \\
Lowest quartile & 0.077 & -0.016 & 0.201 \\
& $(0.001)$ & $(0.001)$ & $(0.016)$ \\
Second quartile & 0.085 & -0.020 & -0.005 \\
& $(0.001)$ & $(0.001)$ & $(0.018)$ \\
Third quartile & 0.089 & -0.022 & -0.106 \\
& $(0.001)$ & $(0.001)$ & $(0.019)$ \\
Highest quartile & 0.099 & -0.024 & -0.522 \\
Women & $(0.001)$ & $(0.001)$ & $(0.019)$ \\
Lowest quartile & & & \\
Second quartile & 0.083 & -0.005 & -0.547 \\
Third quartile & $(0.001)$ & $(0.001)$ & $(0.017)$ \\
Highest quartile & 0.094 & -0.009 & -0.849 \\
& $(0.001)$ & $(0.001)$ & $(0.019)$ \\
& 0.096 & -0.010 & -0.961 \\
& $(0.001)$ & $(0.001)$ & $(0.020)$ \\
& 0.104 & -0.012 & -1.258 \\
& $(0.001)$ & $(0.001)$ & $(0.024)$ \\
\hline
\end{tabular}

Note: Numbers in parentheses are standard errors. The age variable is the difference between the respondent's current age and 52. Each observation is an age-year cell. With the exception of the constant for second quartile males, all coefficients are statistically different from zero at the 1-percent level.

Source: Authors' calculations using tabulations from restricted NLMS data provided by the U.S. Census Bureau, 1979-2011. 
Table 5. Differences in Regression Coefficients, by Educational Quartile

\begin{tabular}{lccc}
\hline & Age & Years since 1979 & Constant \\
\hline Men & & & \\
Difference second and lowest quartile & $0.008^{* * *}$ & $-0.004^{* * *}$ & $-0.201^{* * *}$ \\
& $(0.001)$ & $(0.001)$ & $(0.024)$ \\
Difference third and second quartile & $0.004^{* * *}$ & $-0.002^{* *}$ & $-0.106^{* *}$ \\
& $(0.001)$ & $(0.001)$ & $(0.025)$ \\
Difference highest and third quartile & $0.011^{* * *}$ & $-0.003^{* * *}$ & $-0.416^{* * *}$ \\
Women & $(0.001)$ & $(0.001)$ & $(0.027)$ \\
Difference second and lowest quartile & $0.010^{* * *}$ & $-0.004^{* * *}$ & $-0.302^{* * *}$ \\
& $(0.001)$ & $(0.001)$ & $(0.028)$ \\
Difference third and second quartile & $0.003^{* * *}$ & -0.001 & $-0.111^{* * *}$ \\
& $(0.001)$ & $(0.001)$ & $(0.029)$ \\
Difference highest and third quartile & $0.008^{* * *}$ & $-0.002^{* *}$ & $-0.297^{* * *}$ \\
& $(0.001)$ & $(0.001)$ & $(0.030)$ \\
\hline
\end{tabular}

Note: *** Indicates a statistical difference in the coefficients between the two educational groups at the 1-percent level of significance. ${ }^{* *}$ Indicates a statistical difference in the coefficients between the two educational groups at the 5-percent level of significance. Numbers in parentheses are standard errors on the difference between the two coefficients. The age variable is the difference between the respondent's current age and 52. Each observation is an age-year cell.

Source: Authors' calculations using tabulations from restricted NLMS data provided by the U.S. Census Bureau, 1979-2011. 
Table 6. Period Life Expectancy

1979 cohort 2011 cohort $\quad$ Difference

I. Conditional on surviving to age 65 Men

Lowest quartile

Second quartile

Third quartile

Highest quartile

Women

Lowest quartile

Second quartile

Third quartile

Highest quartile

77.5

77.7

77.8

79.0

82.2

82.5

82.9

83.5

II. Conditional on surviving to age 22

Men

Lowest quartile

Second quartile

Third quartile

Highest quartile

Women

Lowest quartile

Second quartile

Third quartile

Highest quartile

$\begin{array}{lll}68.9 & 75.2 & 6.2 \\ 70.6 & 77.8 & 7.3 \\ 71.3 & 79.0 & 7.7 \\ 74.4 & 82.1 & 7.7\end{array}$

$\begin{array}{lll}77.0 & 78.8 & 1.8\end{array}$

$\begin{array}{lll}78.6 & 81.6 & 3.0\end{array}$

$\begin{array}{lll}79.3 & 82.5 & 3.2\end{array}$

$\begin{array}{lll}80.7 & 84.4 & 3.7\end{array}$

Source: Authors' calculations using tabulations from restricted NLMS data provided by the U.S. Census Bureau, 1979-2011. 
Table 7. Average Annual Mortality Improvements for Whites

\begin{tabular}{lcc}
\hline Years and sample & Men & Women \\
\hline 1979-2011, all ages & & \\
Lowest quartile & -0.014 & -0.001 \\
Second quartile & -0.020 & -0.008 \\
Third quartile & -0.022 & -0.010 \\
Highest quartile & -0.024 & -0.012 \\
& & \\
1990-2011, all ages & & \\
Lowest quartile & -0.017 & -0.006 \\
Second quartile & -0.021 & -0.012 \\
Third quartile & -0.025 & -0.012 \\
Highest quartile & -0.025 & -0.013 \\
& & \\
1999-2011, 45-54 & & \\
Lowest two quartiles & 0.005 & 0.020 \\
Highest two quartiles & -0.010 & -0.025 \\
\hline
\end{tabular}

Note: Represents coefficient on the variable year in a regression of the log of the mortality rate on a constant, age, and year.

Source: Authors' calculations using tabulations from restricted NLMS data provided by the U.S. Census Bureau, 1979-2011. 
Figure 1a. Comparison of NLMS and SSA Mortality Rates (per 100), Men

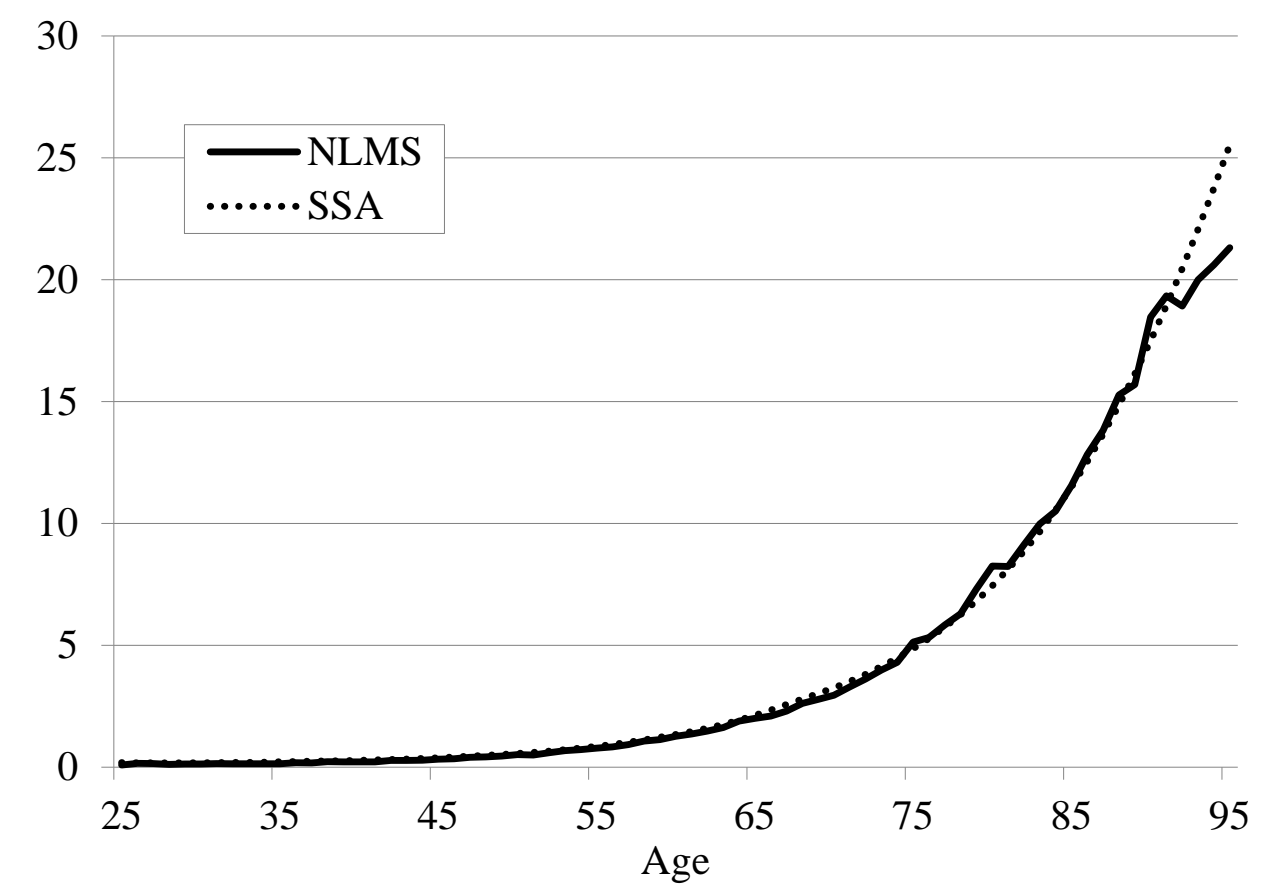

Source: Authors' calculations using tabulations from restricted NLMS data provided by the U.S. Census Bureau, 1979-2011.

Figure 1b. Comparison of NLMS and SSA Mortality Rates (per 100), Women

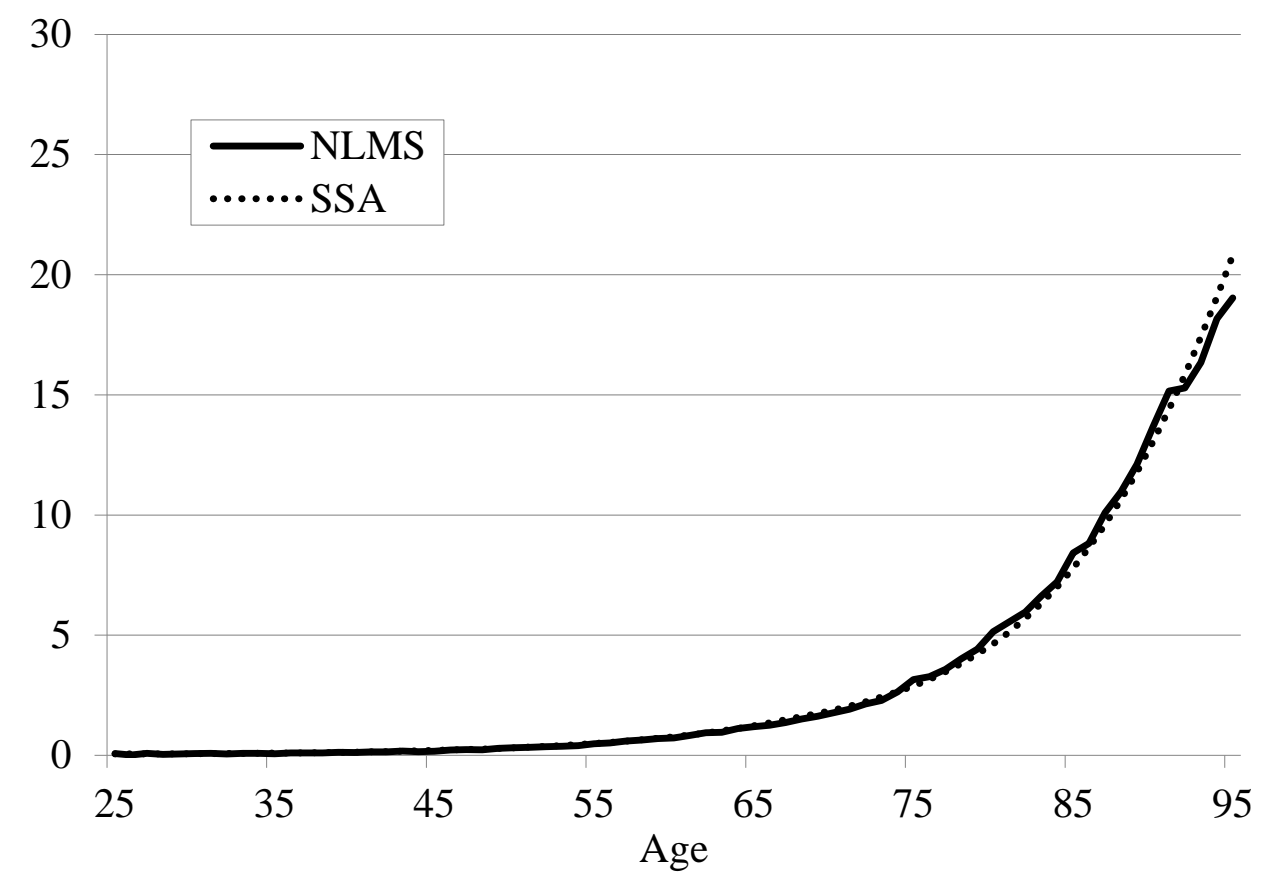

Source: Authors' calculations using tabulations from restricted NLMS data provided by the U.S. Census Bureau, 1979-2011. 
Figure 2a. Comparison of Survival Probabilities for Men in Lowest and Highest Quartiles, 1914 and 1946 Birth Cohorts.

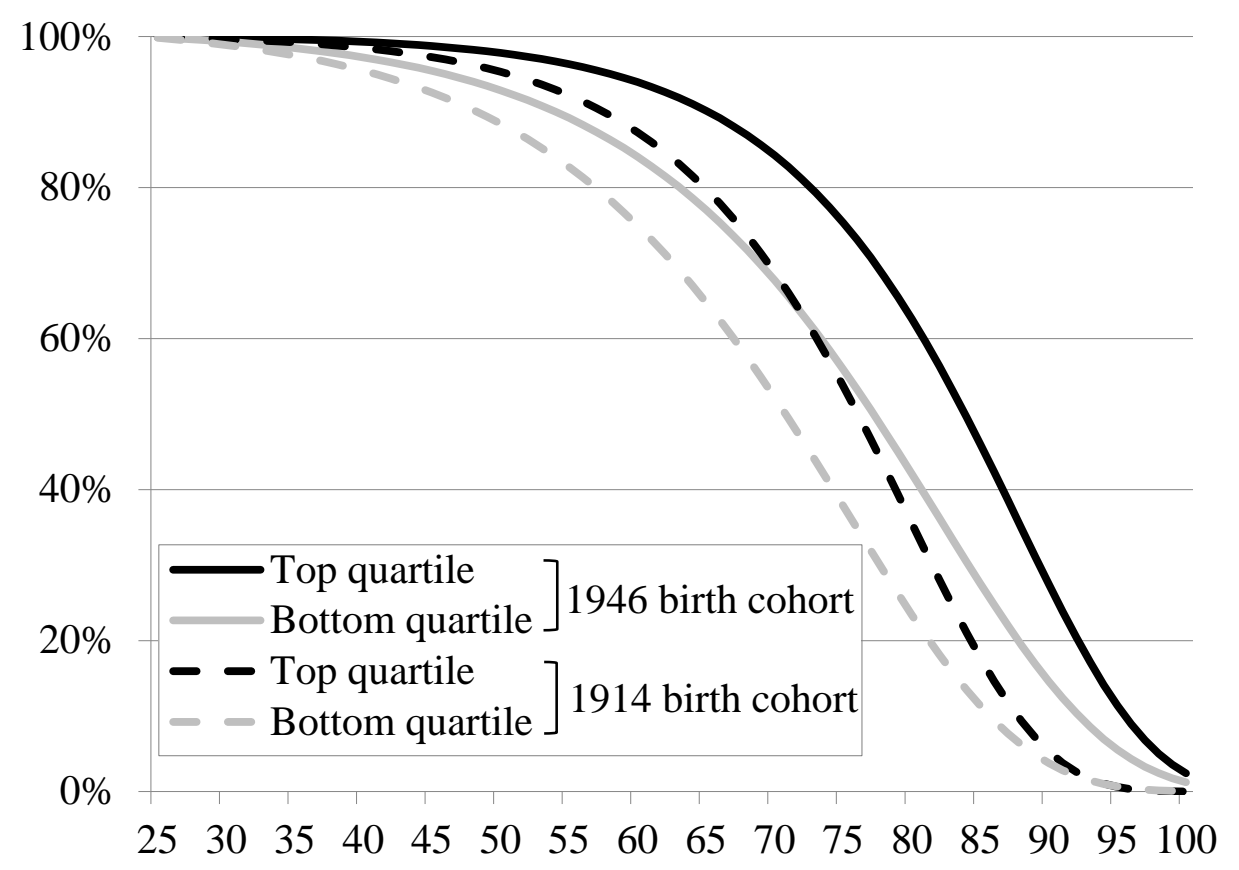

Figure 2b. Comparison of Survival Probabilities for Women in Lowest and Highest Quartiles, 1914 and 1946 Birth Cohorts.

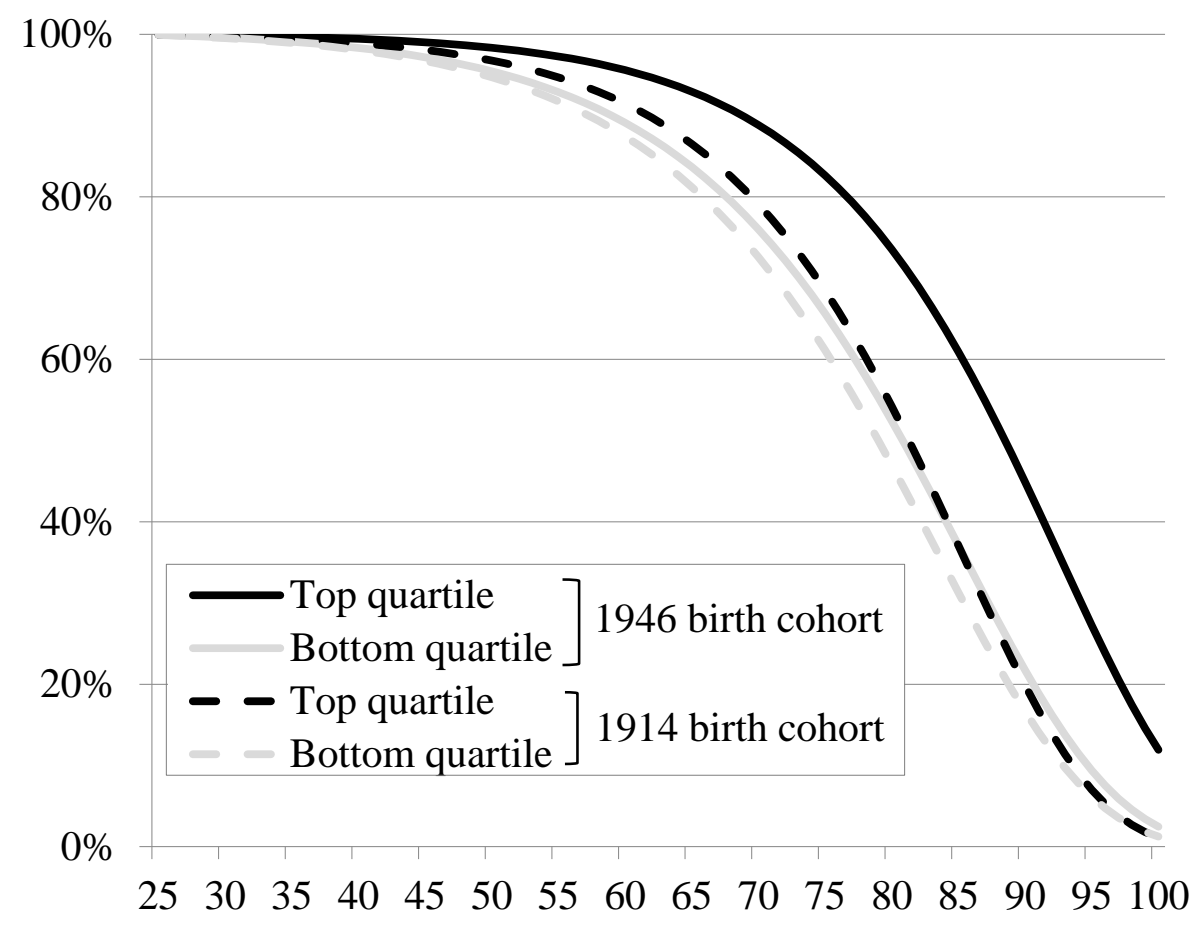

Source: Authors' calculations using tabulations from restricted NLMS data provided by the U.S. Census Bureau, 1979-2011. 
Figure 3. Comparison of Changes in Survival Probabilities between White Men and Women in Lowest Education Quartile, 1914 and 1946 Birth Cohorts.

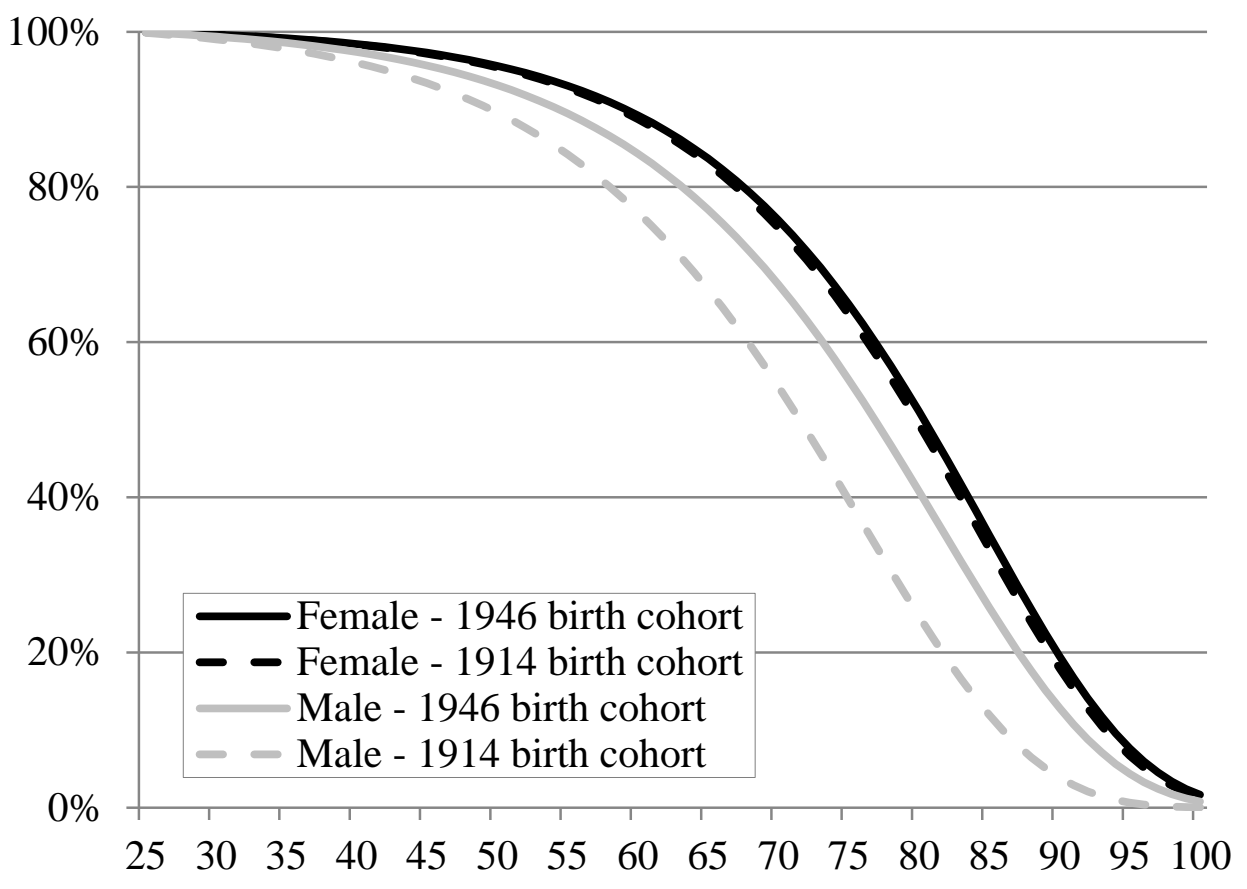

Source: Authors' calculations using tabulations from restricted NLMS data provided by the U.S. Census Bureau, 1979-2011. 


\section{RECENT WORKING PAPERS FROM THE CENTER FOR RETIREMENT RESEARCH AT BOSTON COLLEGE}

The Effect of Job Mobility on Retirement Timing by Education

Geoffrey T. Sanzenbacher, Steven A. Sass, and Christopher M. Gillis, February 2017

Would Reducing the Price of Employing an Older Worker Improve Labor Market Outcomes by Socioeconomic Status? Evidence from Health Insurance Premium Restrictions

Matthew S. Rutledge and Caroline V. Crawford, December 2016

The Impact of Massachusetts Health Insurance Reform on Labor Mobility

Norma B. Coe, Wenliang Hou, Alicia H. Munnell, Patrick J. Purcell, and Matthew S. Rutledge, December 2016

Work, Retirement, and Social Networks at Older Ages

Eleonora Patacchini and Gary V. Engelhardt, November 2016

Calculating Expected Social Security Benefits by Race, Education, and Claiming Age Geoffrey T. Sanzenbacher and Jorge D. Ramos-Mercado, November 2016

Do Late-Career Wages Boost Social Security More for Women than Men? Matthew S. Rutledge and John E. Lindner, November 2016

Cognitive Impairment and Social Security's Representative Payee Program Anek Belbase and Geoffrey T. Sanzenbacher, November 2016

How Would Reducing the Price of Older Workers Improve Labor Market Outcomes by Socioeconomic Status? Evidence from Health Insurance Premium Restrictions Matthew S. Rutledge and Caroline V. Crawford, October 2016

An Overview of the Pension/OPEB Landscape

Alicia H. Munnell and Jean-Pierre Aubry, October 2016

What Are the Effects of Doubling Up on Retirement Income and Assets?

Deirdre Pfeiffer, Katrin B. Anacker, and Brooks Louton, September 2016

How Does Student Debt Affect Early-Career Retirement Saving?

Matthew S. Rutledge, Geoffrey T. Sanzenbacher, and Francis M. Vitagliano, September 2016

The Labor Supply of Disabled Veterans: 1995-2014

Matthew S. Rutledge, Geoffrey T. Sanzenbacher, and Caroline V. Crawford, August 2016

All working papers are available on the Center for Retirement Research website (http://crr.bc.edu) and can be requested by e-mail (crr@bc.edu) or phone (617-552-1762). 